\title{
Comparação entre os métodos de aplicação de fluido de corte convencional e otimizado na retificação plana de cerâmicas
}

\section{(Grinding of alumina ceramics with different cooling and lubrification techniques: conventional and minimum quantity of lubrification (MQL))}

\author{
D.M.Iceri ${ }^{1}$ R.M.e Sousal ${ }^{1}$ R.S.Destro ${ }^{1}$,M.H. Oikawa ${ }^{l}$, \\ E.C.Bianchi ${ }^{1}$, P. R.de Aguiar ${ }^{2}$, C.A. Fortulan ${ }^{3}$ \\ ${ }^{1}$ Departamento de Engenharia Mecânica, ${ }^{2}$ Departamento de Engenharia Elétrica, Universidade Estadual Paulista - \\ UNESP, Campus de Bauru, Av. Luiz Edmundo Carrijo Coube, 14-01, C. P. 473, Bauru, SP 17033-360 \\ ${ }^{3}$ Escola de Engenharia de S. Carlos - USP \\ bianchi@feb.unesp.br
}

\begin{abstract}
Resumo
Com o grande crescimento tecnológico e a necessidade de melhoria, um dos materiais que ganhou uma grande gama na área da engenharia mecânica é a cerâmica, pois possui vantagens físico-químicas e propriedades mecânicas significativas sobre o aço. Entretanto, sua usinagem é um processo difícil e delicado, que requer ainda uma grande atenção em relação ao seu estudo. Assim, o processo de retificação é um dos métodos que tem apresentado bons resultados, porém um grande problema acerca de tal processo é o uso excessivo de fluidos de corte, o que se tornou uma preocupação mundial, já que os fluidos apresentam graves problemas socioambientais, além disso, o fluido de corte é responsável por uma grande parte do custo final do processo, provocando, desse modo, um grande interesse em pesquisas referentes a métodos alternativos de forma a reduzir o consumo e melhorar as características do fluido de corte utilizado. Este trabalho visa comparar duas técnicas de lubri-refrigeração, o método convencional e a Lubrificação Otimizada. O uso do método otimizado é uma alternativa à diminuição do volume de fluido utilizado, já que este tem como princípio a aplicação de uma menor quantidade de fluido de corte com uma alta velocidade, localmente aplicada, ou seja, com essa redução benefícios ambientais e socioeconômicas são obtidos. A análise do trabalho será feita a partir da avaliação das variáveis de saída do processo de retificação plana tais como o comportamento rugosidade e desgaste do rebolo, já que por elas é possível avaliar o processo em relação a qualidade da peça versus custo. Com essas analises, pretende-se avaliar se a técnica otimizada é viável a substituição da refrigeração convencional na retificação plana de cerâmicas.

Palavras-chave: cerâmica, retificação, fluido de corte.
\end{abstract}

\begin{abstract}
The great technological growth and the improvement needs, a material that has gained a wide range in mechanical engineering is the ceramics because of its advantages beyond steel, having chemical and mechanical better properties. However, its machining is a difficult and delicate process, which requires a careful attention to their study. Moreover, the grinding process is one of the methods which is producing good results but, there is a big problem around this, which is the excessive use of cutting fluids that becomes a global concern, since this fluids generate serious social and environmental problems, causing, in this way, a great interest in research on alternative methods to reduce consumption and improve the performance of cutting fluid used. This work aims to compare two techniques of lubrification and cooling in the grinding process, the conventional and the optimized methods. The second one is an option to decrease the volume of fluid used, using the application principle of a smaller amount of cutting fluid applying locally a high speed flow, obtaining environmental and socioeconomic benefits. The analysis of the work will be done based on the evaluation of the output variables of the flat grinding process such as the behavior of the roughness and grinding wheel wear, whereas they can evaluate the process making a relationship between part quality versus cost. With this analysis, we intend to evaluate if the optimized method is a viable substitute to conventional method in the flat grinding process.
\end{abstract}

Keywords: ceramics, grinding, cutting fluid.

\section{INTRODUÇÃO}

Atualmente, com a evolução tecnológica e econômica, as indústrias vêm sofrendo crescente concorrência, tendo a necessidade de se aprimorar cada vez mais, fazendo com que a relação custo/benefício seja elevada. Assim, para o aumento da competitividade de seus produtos, deve-se ter uma alta qualidade, um preço adequado e fabricação em tempo reduzido. Desta forma, a retificação é um dos processos que mais abrange estas necessidades. 
O processo de retificação é bastante complexo e delicado. Isso devido a alguns fatores, tais como, a determinação das condições de dressagem e usinagem, as dificuldades na escolha do rebolo adequado, e por se tratar de uma operação de acabamento, ou seja, a peça possui grandes valores agregados devido ao fato de ter passado por diversos processos e assim qualquer erro cometido nesta etapa pode fazer com que a peça não tenha a precisão desejada.

Retificação é conhecida como o mais complicado processo de usinagem ou de remoção de material, principalmente devido ao fato de a operação de retificação ser realizada por um rebolo que é composto de muitas pequenas, irregulares, afiadas e aleatoriamente posicionados grãos abrasivos ligados por um elemento ligante [1].

Rebolo é o único que diferencia o processo de retificação dos outros processos de usinagem. É conhecido o fato de que a topografia e as condições as quais o rebolo é preparado exercem profunda influência sobre o desempenho da retificação, o que é evidenciado pelas forças de corte, energia consumida, temperatura na zona de corte e muitas vezes no acabamento da peça [2]. Toda energia gerada durante o processo é convertida em calor, que se concentra na zona de corte. Este é atribuído à alta velocidade e ao grande ângulo de inclinação negativo das arestas de corte do rebolo. A alta deformação plástica é causada devido ao desgaste dos grãos que ocorre por causa do aumento do atrito e do carregamento do rebolo que tende a aumentar em função da temperatura da zona de corte [3].

Os fluidos de corte são aplicados na forma de inundações, jato ou neblina, que são as práticas mais comuns para redução da temperatura da zona de corte. Assim, suas funções básicas são de resfriar a peça, retirar os cavacos formados e lubrificar a região de corte. E graças á tais efeitos, há uma redução na força de atrito de fricção entre as faces de apuramentos dos grãos abrasivos e da peça. Dessa forma, a potência de entrada é reduzida e a geração de calor é limitada.

\section{Rebolo}

O rebolo é a ferramenta de corte utilizada no processo de retificação. É composto basicamente por grãos abrasivos ligados a uma matriz aglomerante, tais grãos formam arestas cortantes de geometria indefinida que são responsáveis pela remoção de material. Entre o sistema formado pelos grãos abrasivos e o aglomerante existem poros que influenciam diretamente no desempenho do rebolo, além das propriedades abrasivas do material aglomerante e do tipo de grãos que foi utilizado [4]. A vida do rebolo, a eficiência da retificação e a qualidade superficial da peça estão diretamente ligadas ao tipo de grão abrasivo que é composto o rebolo. Assim a escolha da granulometria dos grãos utilizados na sua fabricação influencia também no desempenho final do processo [5]. Assim o preparo dos grãos antes do início da retificação é de grande importância, a dressagem é uma operação de avivamento ou "reafiação" dos grãos abrasivos. Esta operação consiste em remover ou fraturar grãos desgastados ou limpar o rebolo no caso em que este está empastado (sujo ou "carregado" de cavacos). Destina-se também a remoção do ligante para melhorar a exposição dos grãos abrasivos [6].

\section{Fluidos de corte}

Os fluidos de corte são largamente usados nos processos de retificação para lubrificação, refrigeração e retirada de cavaco. Sua composição é variável dependendo da necessidade do processo em que é usado. Os principais componentes presentes nos fluidos são: refrigerante (água), lubrificantes (óleos minerais, vegetais e sintéticos), inibidores de corrosão (aminas, nitritos, entre outros), umectantes/estabilizantes, bactericidas, aditivos de alta pressão e componentes anti-espumantes. Durante o corte, desenvolve-se uma grande quantidade de calor devido à energia necessária para deformação do cavaco e à energia devido ao atrito ferramenta-peça e cavaco-ferramenta. Este calor gerado precisa ser reduzido (lubrificação) e/ou extraído (refrigeração) da ferramenta e da peça, principalmente a fim de se minimizar o desgaste da ferramenta, a dilatação térmica da peça, e o dano térmico à estrutura superficial da peça [7]. Os fluidos de corte são aplicados na zona de retificação para diminuir a geração de calor. Esse objetivo é alcançado pela redução do atrito na zona de corte, devido à lubrificação da superfície. Isso faz com que se diminuam também os esforços e a potência de corte, pois parte do calor gerado é retirado dessa zona (refrigeração) [8]. Ainda segundo este autor, o fluido é responsável por carregar os cavacos para fora da região de corte. Caso isso não seja feito, há a soldagem deste à ferramenta, ocorrendo a formação de uma aresta postiça de corte. Esse fenômeno modifica o comportamento da ferramenta com relação à força de corte, acabamento superficial da peça, e desgaste da ferramenta.

As pesquisas na área de lubri-refrigerantes intensificaram-se com o objetivo de restringir ao máximo o uso de fluidos de corte na indústria metal-mecânica. Os fatores importantes que justificam tal procedimento incluem os custos operacionais da produção, as questões ecológicas, as exigências legais quanto à preservação do meio ambiente $\mathrm{e}$ à preservação da saúde do ser humano [7].

\section{Desgaste diametral do rebolo}

O desgaste do rebolo se deve a três fatores principais, sendo eles o desgaste do aglomerante, desgaste do grão abrasivo, e friabilidade dos grãos. Trata-se de uma variável de extrema importância no processo de retificação, já que quanto maior o desgaste do rebolo, menor a vida útil deste.

Neste trabalho utilizou-se um rebolo diamantado, pelo fato deste ter a melhor qualidade, atualmente, quando se trata de retificação de cerâmica. Assim, por questões econômicas, torna-se necessário avaliar o desgaste desta ferramenta, buscando sempre a maneira mais eficaz de utilizá-la. O aumento do poder lubrificante proporcionado pelo fluido resulta na diminuição do desgaste do rebolo 
através da redução do atrito grão-peça e do atrito cavacoligante, permitindo que os grãos abrasivos permaneçam por mais tempo ao ligante ocasionando menor desgaste do rebolo [4].

\section{Rugosidade}

A qualidade da topografia da superfície, a rugosidade superficial pode ser definida como o desvio da superfície geométrica ideal. Os sistemas mais comuns de medição da rugosidade são o analisador de contato mecânico e os sistemas ópticos [9]. A rugosidade de uma cerâmica retificada no modo dúctil é anisotrópica (como nos metais), ou seja, tem valores relativamente diferentes dependendo da direção na qual o traçador do rugosímetro faz a leitura. Já as cerâmicas retificadas através do modo frágil apresentam rugosidade mais isotrópica [10]. Recomendações baseadas na ISO 4287/1 são usadas para a execução das medições de rugosidade em cerâmica [9]. A rugosidade é diretamente influenciada pelas variáveis do processo e pelas características do material retificado. Cerâmicas mais dúcteis produzem superfícies menos rugosas e que a microestrutura desempenha papel fundamental, sendo que a média do tamanho de grão da cerâmica determina a rugosidade superficial alcançável. Também citam a importância da escolha do fluido refrigerante e do rebolo na obtenção da rugosidade $[11,12]$

\section{MATERIAIS E MÉTODOS}

Através de ensaios preliminares pode-se montar o banco de ensaios no qual foram definidos os parâmetros de usinagem a serem empregados. Definidos estes foram realizados os ensaios, com os métodos de lubrificação convencional e Otimizado, seguindo os mesmos procedimentos para ambos os casos. Inicialmente, ligou-se o rebolo que permanecia em funcionamento por quinze minutos, para que fosse eliminada qualquer variação inicial do processo. Em seguida foi acionado o fluido de corte, para que o mesmo circulasse por todo o sistema e assim fosse possível a medição da concentração pelo refratômetro ATAGO, modelo N-50E, sendo de $5 \%$ de concentração de fluido tanto para o método Convencional quanto para o Otimizado. Após a dressagem do rebolo foi processada, até se obter uma superfície uniforme, para que o mesmo retificasse a primeira camada do corpo de prova, eliminando as suas irregularidades.
Com todos os procedimentos iniciais realizados, os ensaios propriamente ditos, foram realizados, procedendo com a descida do rebolo de acordo com a espessura de corte definida (20, 70 ou $120 \mu \mathrm{m})$, a cada passada do rebolo pela peça. Os dados dos processos foram captados em tempo real pelos sensores conectados ao computador, através do programa LabView 8.0®. O rebolo diamantado utilizado, comprado da empresa Nikkon Ferramentas Diamantadas, é especificado por D 107 N 115 C50, sendo que a letra D indica o tipo de grão utilizado (diamante), 107 o tamanho do grão utilizado $(107 \mu \mathrm{m})$, a letra $\mathrm{N}$ a dureza do rebolo (dureza média), o valor 115 indica o tipo de diamante e a designação C50 a concentração dos grãos.

A espessura equivalente de corte é um dos importantes parâmetros a ser definido, o qual é determinado pela variação da profundidade de corte, com velocidade da peça e velocidade periférica do rebolo constante, seguindo equação abaixo. Dessa forma foram adotadas as seguintes profundidades de corte: $20 \mu \mathrm{m}, 70 \mu \mathrm{m}$, e $120 \mu \mathrm{m}$, para que assim fosse possível analisar diferentes condições de usinagem, desde a mais severa (desbaste - $120 \mu \mathrm{m}$ ) até a situação mais branda (acabamento - $20 \mu \mathrm{m}$ ).

$$
h_{e q}=\frac{a \cdot V_{w}}{V_{s}}
$$

Outro parâmetro definido para este projeto é o volume específico de material removido, que foi cerca de $2000 \mathrm{~mm}^{3} / \mathrm{mm}$, que foi obtido dividindo o volume que foi retirado pela espessura da peça $(8 \mathrm{~mm})$. Observa-se que será removido uma altura de $17 \mathrm{~mm}$ da peça. Os principais parâmetros do processo de usinagem são apresentados na Tabela I.

Nos ensaios, foram utilizados corpos de prova cerâmicos compostos de alumina calcinada A1000-SG (Almatis, Inc.), cuja composição se encontra na Tabela II. A alumina utilizada é um pó que possui diâmetro médio equivalente de partícula de 0,4 $\mu \mathrm{m}$, área superficial de $7,7 \mathrm{~m}^{2} / \mathrm{g}$ e preal: $3,99 \mathrm{~g} / \mathrm{cm}^{3}$. Sua manufatura foi realizada através de prensagem uniaxial a $1200 \mathrm{MPa}$, sendo mantida em uma estufa de $100{ }^{\circ} \mathrm{C}$ por $12 \mathrm{~h}$, seguida de sinterização durante $2 \mathrm{~h}$ em um forno a $1600{ }^{\circ} \mathrm{C}$. As dimensões das peças são 120 × 60 × 8, em milímetros, onde os valores representam, respectivamente, comprimento, largura e espessura. Além deste corpo de prova, foi utilizada outra peça para a impressão do rebolo, cujas dimensões são 35 x 20 x 9, em

Tabela I - Parâmetros de usinagem.

[Table I - Machining parameters.]

\begin{tabular}{cccc}
\hline $\begin{array}{c}h_{e q}(\text { espessura } \\
\text { equivalente de corte) }\end{array}$ & $\begin{array}{c}A \text { (profundidade } \\
\text { de corte) }\end{array}$ & $\begin{array}{c}V_{w} \text { (velocidade } \\
\text { da peça) }\end{array}$ & $\begin{array}{c}V_{s} \text { (velocidade periférica } \\
\text { do rebolo) }\end{array}$ \\
\hline $0,02 \mathrm{~mm}$ & $20 \mu \mathrm{m}$ & $0,032 \mathrm{~m} / \mathrm{s}$ & $33 \mathrm{~m} / \mathrm{s}$ \\
$0,07 \mathrm{~mm}$ & $70 \mu \mathrm{m}$ & $0,032 \mathrm{~m} / \mathrm{s}$ & $33 \mathrm{~m} / \mathrm{s}$ \\
$0,12 \mathrm{~mm}$ & $120 \mu \mathrm{m}$ & $0,032 \mathrm{~m} / \mathrm{s}$ & $33 \mathrm{~m} / \mathrm{s}$ \\
\hline
\end{tabular}


Tabela II - Composição da alumina calcinada A1000-SG (Almatis, Inc.).

[Table II - Composition of calcined alumina A1000-SG (Altamis,Inc) .]

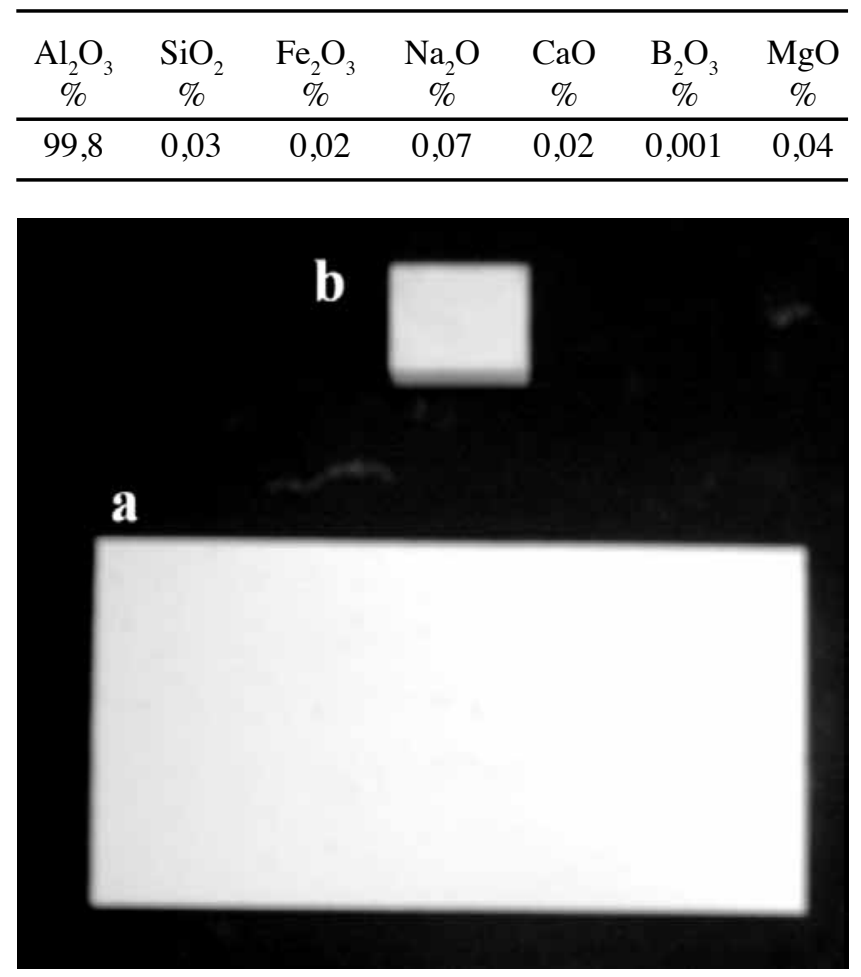

Figura 1: Corpos de provas (a) e peças de marcação do desgaste diametral do rebolo (b).

[Figure 1: Workpieces (a) and pieces to mark the diametral wear of the grinding wheel $(b)$.]

milímetros. A Fig. 1 mostra os corpos de prova do ensaio e de marcação do desgaste.

A execução dos ensaios consistiu na aquisição de dados referente a 5 ciclos de retificação no corpo de prova, para quantificar a condição inicial, sendo removidos 17 mm (16000 $\mathrm{mm}^{3}$ ) na sua altura medição de rugosidade superficial (ou seja, a cada $3200 \mathrm{~mm}^{3}$ de material removido), com o propósito de promover desgaste no rebolo suficiente para medir a relação G. Para a realização dos ensaios foi utilizada uma retificadora tangencial plana da marca SULMECÂNICA, modelo 1055E, onde foram instalados os componentes necessários à análise pretendida, bocais para aplicação de fluido de corte e sensores para captação de dados, de acordo com a Fig. 2.

O fluido de corte utilizado é um óleo solúvel semisintético, ULTRACUT 370, lote número 087402, da empresa ROCOL. Este fluido é um óleo solúvel semi-sintético de alta diluição para usinagem e retífica, facilitando as operações de corte e usinagem, que aumenta a vida útil das ferramentas, possui resistência contra a corrosão e reduz os tempos de operação. A vazão de fluido para cada método de lubrirefrigeração foi de aproximadamente $27,5 \mathrm{~L} / \mathrm{min}$ e $17 \mathrm{~L} / \mathrm{min}$, pressão inferior a $0,2 \mathrm{kgf} / \mathrm{cm}^{2}$ e superior a $0,2 \mathrm{kgf} / \mathrm{cm}^{2}$ e velocidade de aplicação de $3 \mathrm{~m} / \mathrm{s}$ e de $33 \mathrm{~m} / \mathrm{s}$, para o método Convencional e Otimizado, respectivamente. $\mathrm{Ou}$

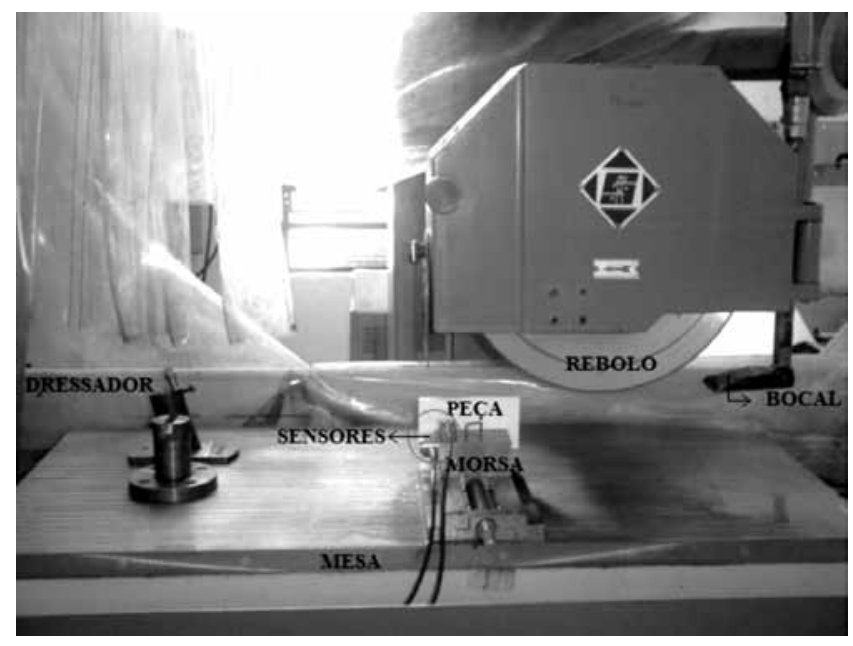

Figura 2: Retificadora plana durante ensaio.

[Figure 2: Plain grinding during test.]

seja, para os dois casos foram utilizados o mesmo fluido de corte, porém o método Otimizado é baseado na redução da quantidade de fluido utilizado (vazão cerca de $38 \%$ menor) com uma velocidade de aplicação maior (cerca de 10 vezes ao do Convencional). Este fluido foi utilizado na proporção de 1:20, ou seja, foram diluídos uma parte de fluido para vinte partes de água, sendo equivalente a concentração de 5\% de fluido. Antes de iniciar os ensaios alguns procedimentos foram feitos tais como o balanceamento do rebolo, fixação da peça na morça e preparo dos fluidos de cortes. Foram utilizados 6 corpos de prova, sendo 3 para cada método de Lubri-refrigeração e cada um para uma profundidade de corte. A cada $400 \mathrm{~mm}^{3} / \mathrm{mm}$ de volume específico de material removido foi medida a rugosidade da peça e feita a marcação para futura medição do desgaste do rebolo, que era a quantidade de material retirada até cada parada.

\section{RESULTADOS E DISCUSSÃO}

Os dois métodos de lubri-refrigeração foram analisados nesta pesquisa, para as diferentes espessuras equivalentes de corte. O acabamento final é uma das qualidades mais importantes das peças, pois influência de forma significativa a resistência à fadiga das peças quando estas são submetidas a esforços, por isso a rugosidade é um dos parâmetros de saída mais essenciais a ser analisado e comparado. A refrigeração, o tamanho dos grãos abrasivos que compõe o rebolo, as condições de dressagem e a taxa de remoção de material (espessura específica) têm grande influência na qualidade final da superfície , ou seja, quanto melhor as condições no qual as peças são usinadas, menor a rugosidade superficial delas [4].

Alguns parâmetros medidos nos processos, usados para analisar os processos foram: emissão acústica, desgaste do rebolo e rugosidade superficial da peça usinada.

Observa-se a partir da Fig. 3 que conforme há um aumento na profundidade de corte, a emissão acústica aumenta, independente do método de lubri-refrigeração 


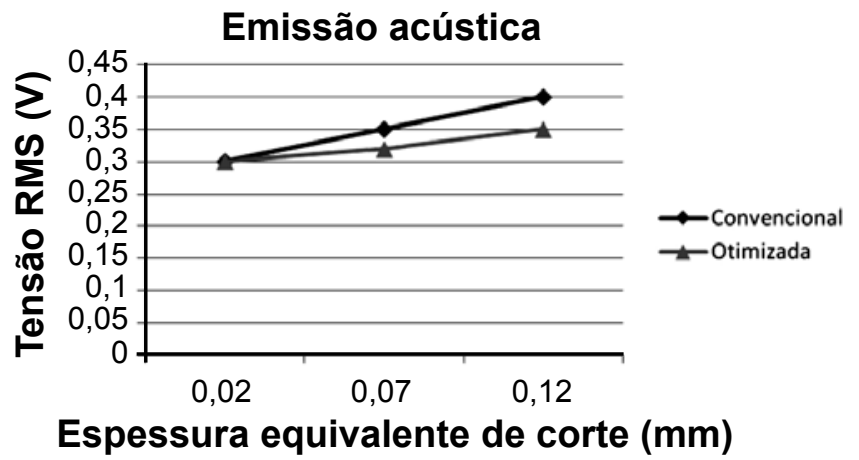

Figura 3: Emissão acústica para os Métodos Convencional e Otimizado.

[Figure 3: Mean roughness to both methods.]

utilizado, isso ocorre, pois à medida que se aumenta à espessura específica o processo de retificação se torna cada vez mais rude, emitindo um ruído maior. O comportamento da emissão acústica é semelhante para ambos os métodos, porém para profundidades de cortes elevados o método Convencional apresentou valores superiores.

O acabamento final é uma das qualidades mais importantes das peças, pois influência de forma significativa à resistência à fadiga das peças quando estas são submetidas a esforços, por isso a rugosidade é um dos parâmetros de saída mais essencial a ser analisado e comparado. A refrigeração, o tamanho dos grãos abrasivos que compõe o rebolo, as condições de dressagem e a taxa de remoção de material (espessura específica) têm grande influência na qualidade final da superfície [4], ou seja, quanto melhor as condições no qual as peças são usinadas, menor a rugosidade superficial delas. A Fig. 4 mostra o comportamento da rugosidade em função do volume específico de material removido, para cada espessura

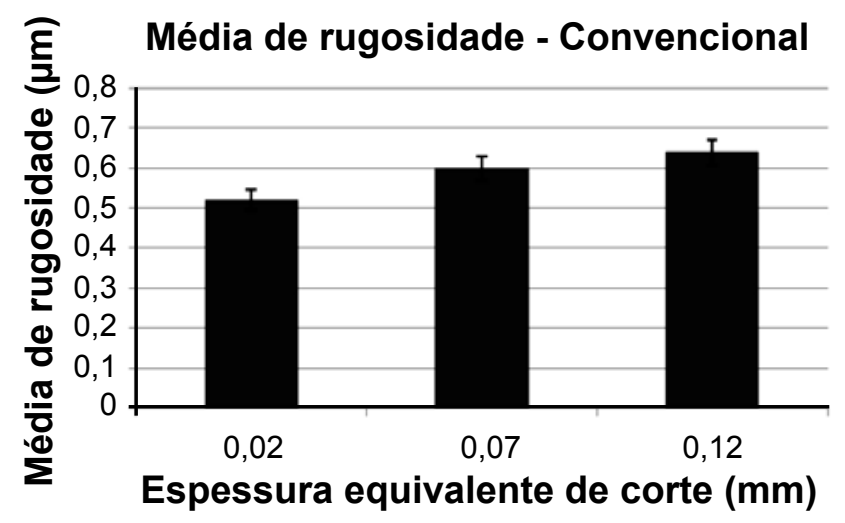

Figura 4: Rugosidade média para o método Convencional [Figure 4: Mean roughness of the Conventional method.]

equivalente de corte ensaiada, na retificação plana de cerâmica pelo método de lubri-refrigeração Convencional.

A Fig. 5 mostra o comportamento da rugosidade em função do volume específico de material removido, para cada espessura equivalente de corte ensaiada, na retificação



Figura 5: Rugosidade média para o método Otimizado. [Figure 5: Mean roughness of the Optimized method.]

plana de cerâmica pelo método da mínima quantidade de lubrificante (MQL).

Verifica-se que a ordem de melhor qualidade superficial foi: o otimizado e convencional, ou seja, pelo método otimizado é pelo qual se resulta em valores de rugosidades menores. E que independente da profundidade de corte essa ordem se manteve, já que sendo a profundidade a mesma, o único fator de influência era a lubrificação. O desgaste do rebolo se deve a três fatores principais, sendo eles o desgaste do aglomerante, desgaste do grão abrasivo, e friabilidade dos grãos. Trata-se de uma variável de extrema importância no processo de retificação, já que quanto maior o desgaste do rebolo, menor a vida útil deste.

A Fig. 6 apresenta os valores médios para o desgaste diametral do rebolo para cada espessura equivalente de corte para os dois tipos de lubri-refrigeração considerados.

Para o método de lubrificação Convencional, verificase claramente a tendência de desgaste cada vez maior. Isto se dá devido ao aumento da profundidade de corte que ao exigir maior força de corte e energia de retificação, gera mais calor e maior atrito na interface peça-ferramenta. Já o comportamento do Método Otimizado é de certa forma linear com relação ao aumento da espessura equivalente de corte. Porém é possível observar que o Otimizado apresenta



Figura 6: Desgaste do rebolo para os métodos Convencional e Otimizado.

[Figure 6: Diametral wear of both methods.] 
menores desgastes do rebolo para todas as situações de retificação.

\section{CONCLUSÕES}

A partir dos resultados obtidos apresentados acima, pode-se concluir que, na retificação plana de cerâmicas para os métodos de lubri-refrigeração Convencional e Otimizado: em relação à rugosidade das peças retificadas, o método otimizado apresentou sempre menores valores quando comparado com os resultados do outro método, apesar destes para o método convencional estar dentro da faixa de tolerância. Quando comparados de forma quantitativa, o método Otimizado possui uma rugosidade cerca de $0,2 \mu \mathrm{m}$ inferior ao método Convencional, portanto quando se exige um bom acabamento superficial o Otimizado é mais eficiente; para o desgaste do rebolo, tem-se que para o método Otimizado os valores foram sempre os menores em todas as espessuras de corte. $\mathrm{O}$ método Convencional apresentou valores altos de desgaste principalmente para a situação mais severa, porém são aceitáveis. Ao se comparar numericamente os dados de desgaste é possível ver uma diferença entre os métodos de aproximadamente $0,01 \mathrm{~mm}$. Dessa forma, o método Otimizado é uma possibilidade muito útil de usinagem, quando se leva em consideração a vida da ferramenta de corte, custos do processo de retificação (devido a redução da quantidade de fluido utilizado e maior vida do rebolo) e a qualidade superficial da peça; Assim, pelas conclusões apresentadas acima, é claro perceber que o método Otimizado leva grande vantagem sobre o método Convencional, sendo possível à substituição do primeiro pelo segundo, já que ele traz também benefícios sócio-ambientais, pois há uma redução significativa da quantidade de fluido de corte utilizado.

\section{REFERÊNCIAS}

[1] T. W. Liao, F. Tang, J. Qu, P. J. Blau, Grinding wheel condition monitoring with boosted minimum distance classifiers, Mechanical Systems Signal Proc. 22 (2008)
217-232.

[2] A. T. Nguyen, D. L. Butler, Correlation of grinding wheel topography and grinding performance: A study from a viewpoint of three-dimensional surface characterization, J. Mater. Proc. Tech. 208 (2008) 14-23.

[3] S. Banerjee, S. Ghosal, T. Dutta, Development of Simple Technique for Improving the Efficacy of Fluid Flow through the Grinding Zone, J. Mater. Proc. Techn. 197 (2008) 306313.

[4] S.Malkin, Grinding Technology: Theory and Applications of Machining with Abrasives, $1^{\text {a }}$ Ed., Chichester, Ellis Horwood Ltd. (1989).

[5] R. D. Monici, Análise da aplicação de vazões reduzidas de fluidos de corte na retificação de aços endurecidos, Diss. Mestrado, Eng. Mec., UNESP, Bauru, SP (2003).

[6] C. E. Stemmer, Ferramentas de corte II: brocas, alargadores, ferramentas de roscar, fresas, brochas, rebolos, abrasivos, Ed. da UFSC, Florianópolis, SC (1992) 314 p.

[7] A. E. Diniz, F. C. Marcondes, N. L. Coppini, Tecnologia da Usinagem dos MateriaisArtbeller Ed., , S. Paulo, SP (2003).

[8] R. A. Irani, R. J. Bauer, A. Warkentin, A review of cutting fluid application in the grinding process, Int. J. Machine Tools \& Manufacture 45 (2005) 1696-1705.

[9] I. Marinescu, M. Pruteanu, Deformation and fracture of ceramics materials, in: L. Marinescu, H. K. Tönshoff, I. Inasaki, Handbook of Ceramic Grinding and Polishing, Noyes Publ., NJ, EUA (1998) Cap. 2.

[10] K. L. Blaedel, J. S. Taylor, C. J. Evans, Ductile-regime grinding of brittle materials, in: S. Jahanmir, M. Ramulu, P. Koshy, Machining Ceramics Composites, Marcel Dekker, EUA (1999) Cap. 5.

[11] S. Jahanmir, H. K. Xu, L. K. Ives, Mechanisms of material removal in abrasive machining of ceramics, in: S. Jahanmir, M. Ramulu, P. Koshy, Machining Ceramics Composites, Marcel Dekker, EUA (1999) Cap. 2.

[12] H. K. Tönshoff, T. Lierse, I. Inasaki, Grinding of advanced ceramics, in: S. Jahanmir, M. Ramulu, P. Koshy, Machining Ceramics Composites, Marcel Dekker, EUA (1999) Cap 3.

(Rec. 14/08/2010, Ac. 14/07/2011) 